\title{
Nuclear Localization of Ataxin-3 Is Required for the Manifestation of Symptoms in SCA3: In Vivo Evidence
}

\author{
Ulrike Bichelmeier, ${ }^{1}$ Thorsten Schmidt, ${ }^{1}$ Jeannette Hübener, ${ }^{1}$ Jana Boy, ${ }^{1}$ Lukas Rüttiger, ${ }^{2}$ Karina Häbig, ${ }^{1}$ Sven Poths, ${ }^{1}$ \\ Michael Bonin, ${ }^{1}$ Marlies Knipper, ${ }^{2}$ Werner J. Schmidt,${ }^{3 \dagger}$ Johannes Wilbertz,${ }^{5}$ Hartwig Wolburg, ${ }^{4}$ Franco Laccone, ${ }^{6}$ and \\ Olaf Riess ${ }^{1}$ \\ Departments of ${ }^{1}$ Medical Genetics and ${ }^{2}$ Otorhinolaryngology, ${ }^{3}$ Zoological Institute, Neuropharmacology, and ${ }^{4}$ Institute for Pathology, University of \\ Tübingen, D-72076 Tübingen, Germany, ${ }^{5}$ Department of Cell and Molecular Biology, Karolinska Institute, SE-171 77 Stockholm, Sweden, and ${ }^{6}$ Department \\ of Medical Genetics, University of Vienna, A-1090 Vienna, Austria
}

\begin{abstract}
Spinocerebellar ataxia type 3 (SCA3) is an autosomal dominantly inherited neurodegenerative disorder caused by the expansion of a CAG repeat in the MJD1 gene resulting in an expanded polyglutamine repeat in the ataxin-3 protein. To study the course of the disease, we generated transgenic mice for SCA3 using full-length ataxin-3 constructs containing 15, 70, or 148 CAG repeats, respectively. Control mice (15 CAGs) were phenotypically normal and had no neuropathological findings. However, mice transgenic for ataxin-3 with expanded polyglutamine repeats were severely affected by a strong neurological phenotype with tremor, behavioral deficits, strongly reduced motor and exploratory activity, a hunchback, and premature death at 3 to 6 months of age. Neuropathological examination by immunohistochemical staining revealed ubiquitin- and ataxin-3-positive intranuclear inclusion bodies in a multitude of neurons. Directing ataxin-3 with 148 CAGs to the nucleus revealed an even more pronounced phenotype with more inclusions and earlier death, whereas mice transgenic with the same construct but attached to a nuclear export signal developed a milder phenotype with less inclusions. These studies indicate that nuclear localization of ataxin-3 is required for the manifestation of symptoms in SCA3 in vivo.
\end{abstract}

Key words: neurodegenerative diseases; polyglutamine diseases; spinocerebellar ataxia type 3 (SCA3); Machado-Joseph disease (MJD); mouse model; nuclear localization

\section{Introduction}

Spinocerebellar ataxia type 3 (SCA3) or Machado-Joseph disease (MJD) is an autosomal dominantly inherited neurodegenerative disorder caused by the expansion of a CAG stretch in the MJD1 gene encoding a polyglutamine repeat in the respective ataxin-3 protein (Kawaguchi et al., 1994). Until now, nine neurodegenerative diseases, including SCA3, are known to share the same type of mutation and were therefore grouped as polyglutamine diseases: SCA1-SCA3, SCA6, SCA7, SCA17, dentatorubralpallidoluysian atrophy (DRPLA), spinal and bulbar muscular atrophy (SBMA), and Huntington's disease (HD) (for review, see Schöls et al., 2004).

Whereas the number of CAG repeats in the MJD1 gene range between 12 and 40 in control individuals, the repeat is expanded

\footnotetext{
Received Nov. 10, 2005; revised June 1, 2007; accepted June 4, 2007.

This work was supported by the German Research Foundation under contract number RI 682/7-1/2/3 to 0.R. as a part of the German SCA3 Research Group. We thank Prof. Mathias Jucker and his group for granting us access to their microscopes, Peter Breuer for providing us his anti-ataxin-3 antibody, and Hoa Nguyen for critical reading of this manuscript. We are grateful to Ria Knittel and Gabi Frommer-Kästle for help with the electron microscopy and to Marc Niwar for expert technical assistance.

${ }^{\dagger}$ During the review process of this manuscript, our coauthor Werner J. Schmidt suddenly died. We publish this study in his memory and are deeply grateful for his outstanding collaboration.

*T.S. and J.H. contributed equally to this work.

Correspondence should be addressed to Olaf Riess, Department of Medical Genetics, University of Tübingen, Calwerstrasse 7, D-72076 Tübingen, Germany.E-mail: Olaf.Riess@med.uni-tuebingen.de.

D0I:10.1523/JNEUROSCI.4540-06.2007

Copyright $\odot 2007$ Society for Neuroscience $\quad$ 0270-6474/07/277418-11\$15.00/0
}

to $>53$ CAG repeats in SCA3 patients (van de Warrenburg et al., 2002; Schöls et al., 2004). Clinical symptoms usually manifest between the ages of 30 and 50, causing premature death (Dürr et al., 1996; Schöls et al., 1997).

Histopathological examinations of postmortem brains of SCA3 patients revealed degeneration and loss of neuronal cells in characteristic brain regions (Takiyama et al., 1994). Other important histopathological hallmarks of SCA3 are protein aggregates in the nucleus of neuronal cells in affected patients, the neuronal intranuclear inclusion bodies (NIIs). Originally, NIIs were detected exclusively in affected brain regions (Paulson et al., 1997b; Schmidt et al., 1998) but were more recently also observed in brain regions that usually appear to be spared from neurodegeneration (Yamada et al., 2001). Similarly, protein aggregates in the nucleus were also observed in SCA1, SCA2, SCA7, SCA17, DRPLA, SBMA, and HD (for review, see Schöls et al., 2004). In some cases of SCA2 (Huynh et al., 2000), SCA6 (Ishikawa et al., 1999), and HD (DiFiglia et al., 1997), protein aggregates have been identified either additionally or exclusively in the cytoplasm.

In contrast to the proteins altered in SCA1 (Servadio et al., 1995), SCA7 (Kaytor et al., 1999), and SCA17 (Nakamura et al., 2001), ataxin-3 is primarily localized in the cytoplasm (Paulson et al., 1997a; Schmidt et al., 1998), and nuclear localization was observed only in a few cells (Tait et al., 1998; Trottier et al., 1998). It is essentially unknown how ataxin-3 enters the nucleus of certain cells under pathogenic conditions and forms aggregates. 
Also, for SCA3, it is widely unknown whether nuclear localization of the aberrant protein is important or even essential for the manifestation of a phenotype. In HD, for instance, cytoplasmic inclusions are thought to contribute to the development of the phenotype (Cooper et al., 1998).

To address some of these questions, we generated various mouse models of SCA3 using full-length ataxin-3 constructs. We demonstrate in vivo that nuclear localization of ataxin-3 is required for the generation of symptoms and that export of ataxin- 3 out of the nucleus prevents the manifestation of a phenotype.

\section{Materials and Methods}

Generation of transgenic mice. A full-length ataxin-3 construct (ataxin-3c isoform) (Goto et al., 1997; Schmitt et al., 1997) containing 15, 70, or 148 CAG repeats was used for the generation of the SCA3 mouse model. The CAG repeat was extended to 148 CAG repeats, as described previously (Laccone, 2002). To control the expression of the ataxin-3 transgene, we used a $3.4 \mathrm{~kb}$ fragment of the murine prion protein (Prp) promoter containing $1140 \mathrm{bp}$ of the murine prion protein gene upstream of exon 1 , the complete exon 1 , intron 1 , and the first 52 bp of exon 2 . This fragment corresponds to base pairs 37-3462 in the GenBank entry U52821. Primers phg_Prp_Xba_FP (5'-GCTCTAGAGCCAATCTTGTGTCTGG-3') and phg_Prp_Bam_RP (5'-CGGGATCCCGGAATGCTTCAGCTCGG$3^{\prime}$ ) were used to amplify the prion protein promoter fragment by PCR.

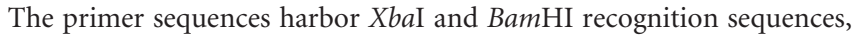
respectively, to allow the cloning of the prion protein promoter in front of the ataxin-3 gene in the pBluescript II KS vector.

For nuclear targeting of ataxin-3, three repeats of the nuclear localization signal from the simian virus 40 (SV40) T antigen (PKKKRKV) (Kalderon et al., 1984) were cloned at the $\mathrm{C}$ terminus of ataxin-3. To transport ataxin-3 into the cytoplasm, the nuclear export signal (NES) of the heat-stable inhibitor of the cAMP-dependent protein kinase [protein kinase inhibitor (PKI)] (LALKLAGLDI) (Wen et al., 1995) was likewise attached to ataxin-3. Constructs with localization signals were additionally tagged C-terminally either with a Myc or a Flag tag. Between the localization signal and the tag, the four amino acids PGPG were inserted as "helix breaker." All constructs were completed with a SV40 polyadenylation signal. The generated constructs in the vector pBluescript II KS were linearized using NotI and BglI and injected into fertilized murine oocytes of the C57BL/6N mouse strain.

DNA isolation and mouse genotyping. For genotyping of transgenic mice, DNA was isolated from ear biopsy tissue. Protein was digested overnight at $55^{\circ} \mathrm{C}$ in proteinase $\mathrm{K}$ buffer $(350 \mu \mathrm{g}$ of proteinase $\mathrm{K}$ in $50 \mathrm{~mm}$ Tris, pH 8.0; $100 \mathrm{~mm}$ EDTA; and $100 \mathrm{~mm} \mathrm{NaCl}, 1 \%$ SDS) and, after the addition of saturated $\mathrm{NaCl}$ solution, removed by centrifugation. RNA was digested using RNase A (Sigma-Aldrich, Munich, Germany) for $15 \mathrm{~min}$ at $37^{\circ} \mathrm{C}$. After precipitation with isopropanol and incubation at room temperature (10 $\mathrm{min}$ ), DNA was separated by centrifugation [30 $\mathrm{min}, 20,000$ relative centrifugal force $(\mathrm{rcf})$ at $4^{\circ} \mathrm{C}$ ], washed with $70 \%$ ethanol, and resuspended in TE (10 mM Tris, pH 8.0, and 1 mM EDTA). For PCR genotyping, the primers PrP-SphI-F1 (5'-TTTGGAATATGTTTGCGCTG- $\left.3^{\prime}\right)$ and MJD-R (5'-AGTTGGTCAGCTTCGCAATC-3') were used with BioTherm Taq DNA Polymerase (GeneCraft, Lüdinghausen, Germany) according to the manufacturer's recommendation and supplemented with Q-solution (Qiagen, Hilden, Germany). The amplification conditions were as follows: 5 min at $94^{\circ} \mathrm{C} ; 35$ cycles of $45 \mathrm{~s}$ at $94^{\circ} \mathrm{C}, 1 \mathrm{~min}$ at $58^{\circ} \mathrm{C}, 1 \mathrm{~min}$ and $30 \mathrm{~s}$ at $72^{\circ} \mathrm{C}$; and a final extension for $7 \mathrm{~min}$ at $72^{\circ} \mathrm{C}$ in a GeneAmp PCR System 9700 (Applied Biosystems, Foster City, CA).

Quantitative real-time reverse transcription-PCR. RNA from whole brain was isolated using RNeasy (Qiagen). RNA quality was validated using a RNA 6000 NanoChip (Agilent Technologies, Böblingen, Germany), subjected to cDNA synthesis using the Transcriptor First Strand cDNA Synthesis kit (Roche Applied Science, Mannheim, Germany), amplified using a LightCycler TaqMan Master kit (Roche Applied Science), and analyzed in triplicates using a LightCycler 480 system (Roche Applied Science) using Universal ProbeLibrary probes (Roche Applied Science) for detection. For ataxin-3, we used the primers 5'-GTGGTG-
GTGCGAGTCTACAA-3' and 5'-GCTGACCTCAAACTCAGAGCA-3' and to amplify the reference gene pyruvate dehydrogenase, the primers 5'-GAGCTGAGATTTGTGCCAGA-3' and 5'-CAGGGGCATCAAGGAAGTT-3' were used.

Western blot analyses. Mice were killed, and the tissue was freshly prepared, immediately snap frozen, and stored at $-80^{\circ} \mathrm{C}$. For protein isolation, tissue was homogenized at 30,000 rpm using a tissue homogenizer (Ultra-Turrax; IKA Werke, Staufen, Germany) in TES buffer (50 mM Tris, pH 7.5, 2 mM EDTA, and $100 \mathrm{~mm} \mathrm{NaCl}$ ) supplemented with a mixture of protease inhibitors (complete; Roche Applied Science). After the addition of Nonidet NP-40 (Sigma-Aldrich) to a final concentration of $1 \%$ and incubation at $4^{\circ} \mathrm{C}$ for $15 \mathrm{~min}$, debris was removed by centrifugation $\left(15 \mathrm{~min}\right.$ each, $\left.20,000 \mathrm{rcf}, 4^{\circ} \mathrm{C}\right)$. The cleared protein extract was supplemented with glycerol (final concentration of $10 \%$; VWR International, Darmstadt, Germany) and stored at $-80^{\circ} \mathrm{C}$.

The protein concentration was determined using a protein assay (Protein Assay Dye Reagent Concentrate; Bio-Rad, Munich, Germany) based on the method described by Bradford (1976) according to the manufacturer's instructions.

Protein extracts (30 $\mu \mathrm{g}$ of each) were supplemented with loading buffer ( 80 mм Tris, pH 6.8, 0.1 м DTT, 2\% SDS, 10\% glycerol, bromphenol blue), denatured, and analyzed in PAGE buffer (192 mM glycine, 25 mM Tris, 1\% SDS) using SDS-PAGE (Blue Vertical 100/C; Serva, Heidelberg, Germany) according to the method described by Laemmli (1970). Separated proteins were transferred to nitrocellulose (Whatman, Dassel, Germany) in transfer buffer ( $0.2 \mathrm{~m}$ glycine, $25 \mathrm{~mm}$ Tris, $20 \%$ methanol). The detection of the protein was performed essentially as described previously (Schmidt et al., 1998). Briefly, the membrane was blocked in 5\% dry milk in TBST buffer ( $10 \mathrm{~mm}$ Tris, $\mathrm{pH} 7.5,0.15 \mathrm{~m} \mathrm{NaCl}, 0.1 \%$ Tween 20) for $2 \mathrm{~h}$ at room temperature. The primary antibody was diluted in TBST.

The generation of our anti-ataxin-3 antibody (diluted 1:1000) has been described previously (Schmidt et al., 1998). The 1H9 antibody against ataxin-3, as well as the 1C2 antibody directed against expanded polyglutamines were purchased from Chemicon (Hofheim, Germany). Antibodies against myc-tag (Santa Cruz Biotechnology, Santa Cruz, CA), and Flag-tag (Sigma-Aldrich) were also purchased commercially.

After incubation for $2 \mathrm{~h}$, the membrane was washed four times with TBST for $15 \mathrm{~min}$. The secondary antibody was coupled to horseradish peroxidase (GE Healthcare, Freiburg, Germany) and incubated with the membrane for $75 \mathrm{~min}$. After four washing steps with TBST (15 min each), bands were visualized using the enhanced chemiluminescence method (ECL; GE Healthcare) by exposure to Hyperfilm ECL (GE Healthcare).

Immunofluorescence and immunohistochemistry. Cells were grown on coverslips coated with $0.01 \%$ poly-L-lysine (Sigma-Aldrich), washed with PBS, and fixed with ice-cold methanol/acetone for $10 \mathrm{~min}$. After washing with PBS, cells were blocked using 3\% normal donkey serum in PBS. After washing with PBS, the primary antibody [anti-Flag-tag (Sigma-Aldrich), diluted in 3\% donkey serum] was added and incubated for $1 \mathrm{~h}$ at room temperature. Cells were washed with PBS and incubated with the secondary antibody (cyanine 2-coupled anti-mouse-antibody; Jackson ImmunoResearch, West Grove, PA) diluted in 3\% donkey serum. Cells were again washed four times with PBS and mounted on slides using Mowiol (Merck, Darmstadt, Germany) supplemented with 2.5\% DABCO (1,4-diazabicyclo[2.2.2] octane; Sigma-Aldrich). Fluorescent signals were observed by epifluorescence.

The immunohistochemical staining of paraffin-embedded tissue was performed as described previously (Schmidt et al., 2002). Briefly, after rehydrating the sections in xylene and a graded alcohol series, slides were, if necessary, microwaved for $15 \mathrm{~min}$ in $10 \mathrm{~mm}$ sodium citrate, $\mathrm{pH}$ 6.0. Slides were washed with PBS; endogenous peroxidases were blocked using $1 \%$ hydrogen peroxide in $40 \%$ methanol for 10 min and blocked using 5\% normal goat serum in PBS supplemented with $0.3 \%$ Triton. After washing with PBS (three times for $10 \mathrm{~min}$ ), the primary antibody (diluted in PBS plus 3\% goat serum) was added and incubated at $4{ }^{\circ} \mathrm{C}$ overnight in a humid chamber. The secondary antibody was coupled with biotin (Vector Laboratories, Burlingame, CA), diluted the same way in PBS plus $1.5 \%$ goat serum, and added after washing the slides with 
PBS. After incubation for $30 \mathrm{~min}$ at room temperature and a brief wash with PBS, an ABC enhancer complex coupled with peroxidase (Vector Laboratories) was added and incubated for $30 \mathrm{~min}$ at room temperature. After washing with PBS, the substrate (DAB; Sigma-Aldrich) was added, and the reaction was stopped in distilled water after the desired degree of straining was reached. If necessary, slides were counterstained with hematoxylin (Merck). Finally, slides were dehydrated again and mounted using CV mount (Leica, Bensheim, Germany). The antibodies against ubiquitin and phosphorylated neurofilaments were purchased from Dako Deutschland (Hamburg, Germany) and Sigma-Aldrich, respectively.

Staining was visualized using an Axioplan 2 imaging microscope (Carl Zeiss Microimaging, Oberkochen, Germany) equipped with an AxioCam HR color digital camera (Carl Zeiss Microimaging) using a $40 \times$ Plan Neofluar and a $63 \times$ Plan/Apochromat objective and the AxioVision 4.3 software package (Carl Zeiss Microimaging). Statistical analysis of the number of neurons with inclusion bodies was performed by counting at least 10 randomly selected fields of vision per brain region with an average of $\sim 100$ neurons.

Electron microscopy. Electron microscopic analyses were essentially performed as described previously (Lundkvist et al., 2004). Briefly, brains were dehydrated in ethanol and incubated overnight in $70 \%$ ethanol saturated with uranyl acetate. After additional dehydration in absolute ethanol and propylene oxide, the samples were embedded in Araldite 502 (Sigma-Aldrich) and sectioned on a Leica FCR Ultracut ultramicrotome (Leica). Ultrathin sections were stained with uranyl acetate and lead citrate and examined with a Zeiss EM 10 electron microscope.

Laboratory parameters. Blood of two transgenic SCA3 mice (line 70.61) and of two negative littermates as controls was analyzed for a whole set of 18 laboratory parameters by Vet Med Labor (Ludwigsburg, Germany). For kidney profile, the concentrations of urea, creatine, total protein, and anorganic phosphate were determined. To profile the liver, we determined the enzyme values of the aspartate aminotransferase, glutamate dehydrogenase, and alkaline phosphatase and analyzed bilirubin and albumin concentrations. Function of pancreas was profiled by measuring glucose and cholesterol concentration and lipase and $\alpha$-amylase enzyme values. For the muscle profile, creatinine kinase and lactate dehydrogenase were determined as well as the concentration of calcium, magnesium, and total triglyceride.

Neurochemistry. Neurochemical analysis based on the method described by Kilpatrick et al. (1986) was essentially performed as described previously (Srinivasan and Schmidt, 2004). Briefly, brains of killed mice were removed immediately, and the striatum was dissected with a mouse brain matrix for coronal slices (World Precision Instruments, Sarasota, FL). The tissue content of dopamine, its metabolites 3,4-dihydroxyphenylacetic acid (DOPAC), homovanillic acid (HVA), and 3-MT (3methoxytyramine) as well as 5-hydroxytryptamine (5-HT; serotonin) and its metabolite 5-hydroxyindoleacetic acid (5-HIAA) were analyzed by HPLC. Samples were autoinjected (Microsampler CMA 200; CMA Microdialysis, Solna, Sweden) into a reversed-phase column (Spherisorb ODSII; Bischoff, Leonberg, Germany) and detected electrochemically (ESA 5010; Bischoff). HPLC data were analyzed using the Axxiom 727 software (Sykam, Gilching, Germany) and presented in picograms of substance per milligram of wet tissue. Dopamine and serotonin turnover rates were calculated according to Masilamoni et al. (2005) by using the following formulas: dopamine turnover $=(($ DOPAC + HVA $) /$ dopamine $)$, and serotonin turnover $=(5$-HIAA/5-HT). Five 3-month-old male transgenic mice $(70 \mathrm{CAG}$ repeats) were analyzed and compared with wild-type littermates as controls.

Phenotypic analyses. We used several different tests for phenotypical assessment of our mouse models. For a first screening, a battery of 24 basic phenotypical analyses were performed using a modified SHIRPA protocol containing tests for autonomic, sensory, spinocerebellar, neuropsychiatric, muscle, and lower motor neuron function (Rogers et al., 1997; Green et al., 2005).

For gait analysis, footprint patterns were recorded. Forelimbs of the mice were stained with red and hindlimbs with blue nontoxic paint. Mice were placed on a sheet of paper (A3 size) in front of a tunnel $(\sim 5 \times 5 \times$ $60 \mathrm{~cm}$ ). Only the middle steps of a series of steps were analyzed for accuracy of the gait and measuring distance between two steps. For sta-

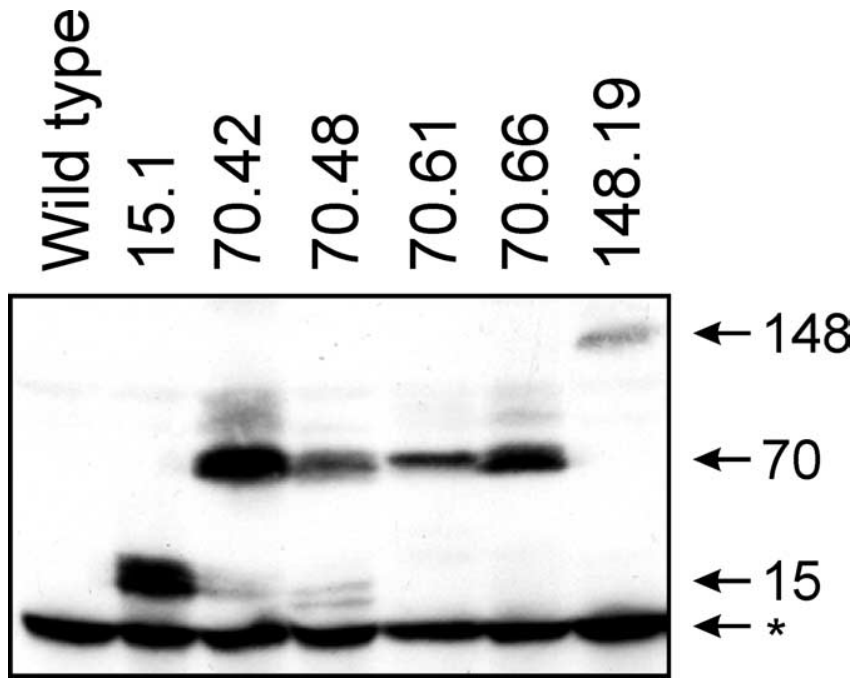

Figure 1. Expression of ataxin-3 constructs in different transgenic mouse lines. The Western blot analysis using an anti-ataxin-3 antibody (kindly provided by Peter Breuer, University of Bonn, Bonn, Germany) shows expression of ataxin-3 in whole brain extract of different transgenic SCA3 mouse lines containing an ataxin-3 construct with a variable number of CAG repeats $(15,70$, and 148 , respectively). The mouse lines are named after the transgene and the number of the line (e.g., line 61 of the mice with 70 CAG repeats is 70.61). Mice of the strongly affected lines (70.61 and 148.19) were analyzed at 3 months of age, of the other lines at 11 months of age. For comparison, brain extract of a wild-type mouse is shown. Arrows mark the ataxin-3 transgenes and the number of (AG repeats. Endogenous ataxin- 3 is marked with an asterisk $\left({ }^{*}\right)$. Comparable analyses with additional anti-ataxin-3 antibodies confirmed the identity of the marked bands (data not shown). Low signal intensities in lines 70.61 and 148.19 reflect the reduced availability of soluble ataxin-3 caused by the formation of insoluble intranuclear aggregates.

tistical analysis, three to four mice of each mouse line and 30 steps were analyzed and measured, respectively.

The pen test was applied to assess motor coordination. A mouse hold on its tail was slowly lowered from above to a pen (diameter, $\sim 1 \mathrm{~cm}$ ) fixed $\sim 25 \mathrm{~cm}$ above ground. Usually, the mouse grabs for the pen and starts walking on it without difficulties. Any difference to this usual behavior was recorded.

Hearing measurements. Anesthesia of animals, measurements of auditory brainstem responses (ABRs), and the cubic distortion product of the otoacoustic emissions (DPOAEs) were performed as described previously (Knipper et al., 2000; Schimmang et al., 2003; Carnicero et al., 2004). Briefly, ABR thresholds were determined with click (100 $\mu \mathrm{s})$ or pure tone stimuli $(2-45 \mathrm{kHz})$. Outer hair cell function was assessed by the growth function of the DPOAEs. Data are presented as mean and SD.

\section{Results}

\section{Generation of SCA3 mouse models}

To generate mouse models of SCA3, full-length constructs of human ataxin-3 (isoform ataxin- $3 c$ that contains an additional ubiquitin-interacting motif at its C terminus) (Goto et al., 1997; Schmitt et al., 1997; Albrecht et al., 2004) under control of the murine prion protein promoter were injected into the C57BL/6 mouse background. Two different expanded repeat lengths were used: 70 CAG repeats and 148 CAG repeats, respectively. As controls, transgenic mice were generated with the same construct but containing only 15 CAG repeats.

\section{Mice expressing human ataxin-3 with 15 CAG repeats are phenotypically normal}

To explore whether (over)expression of human wild-type fulllength ataxin-3 itself induces a phenotype, we generated transgenic mice using the ataxin-3c cDNA containing 15 CAG repeats. For this construct, four stable transgenic mouse lines were gen- 
A

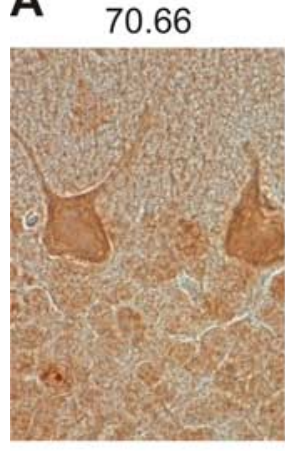

B

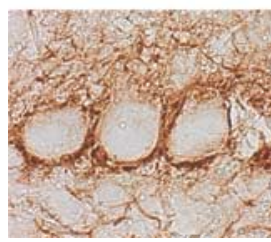

70.61

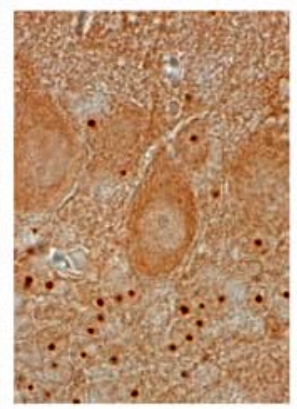

70.61

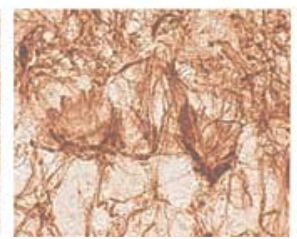

70.48

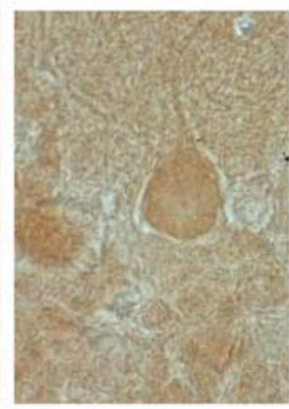

NLS.61

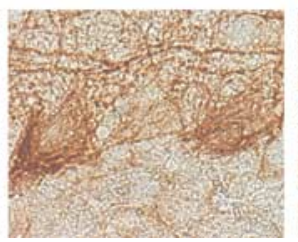

Figure 2. Cerebellar sections of transgenic SCA3 mice. $\boldsymbol{A}$, Cerebellar tissue from different mouse lines with 70 CAG repeats at 1 year of age (except for line 70.61, at 4 months of age) were stained with an anti-ataxin-3 antibody. Ataxin-3 aggregates in cells of the granular layer of the cerebellum are especially prominent in line 70.61. No inclusion bodies were identified in Purkinje cells. Scale bar, $20 \mu \mathrm{m}$. B, Cerebellar tissue from different SCA3 mice with 15 and 70 CAG repeats as well as with 148 CAG repeats supplemented with a NLS or NES signal, respectively, was stained with an anti-phosphorylated neurofilament antibody. The formation of contracted or empty baskets around Purkinje cells is apparent in the model with 70 CAG repeats. An increase of basket formation is also visible in the NLS model even if not so marked. The NES model appears to be almost unchanged, similarly to transgenic control mice (15 CAG repeats). Ages of the mice: 15 CAG and NES, 1 year; 70 CAG and NLS, 4 months. Scale bar, $20 \mu \mathrm{m}$.

erated. Western blot analysis of brain tissue confirmed the expression of transgenic ataxin-3 protein (Fig. 1) (mouse line 15.1 is shown as one example). Immunohistochemical analysis of mice at 1 year of age revealed an overall cytoplasmic localization of ataxin-3 and no obvious neuropathological phenotype. In particular, protein aggregates or inclusion bodies were not detected in the brain (data not shown). Phenotypic analyses of mice at different ages and from different mouse lines did not demonstrate any significant difference to wild-type control mice applying a modified SHIRPA protocol (Green et al., 2005).

We thus conclude that the expression of human ataxin-3c with 15 CAG repeats does not cause a neurological phenotype in mice. Therefore, these mouse lines were used for additional comparison with the SCA3 disease models.

\section{Mice transgenic for ataxin-3 with 70 polyglutamine repeats develop a severe phenotype}

As disease models, we generated transgenic mice containing 70 CAG repeats. For this construct, four stable mouse lines were established and analyzed. Expression of the transgene was confirmed by Western blotting [Fig. 1 (70.42, 70.48, 70.61, and 70.66, respectively)]. Mice from two transgenic lines (70.42 and 70.66) developed a mild but noticeable phenotype. Mice from line 70.42 developed obvious neurological symptoms at 5-6 months of age and died $\sim 6$ months later. Histochemical analysis of brain slices from these mice revealed scattered cortical neurons with intranuclear inclusion bodies. In line $70.66, \sim 0.5 \%$ of the cortical and $\sim 10 \%$ of the cerebellar neurons contained intranuclear inclusion bodies at 1 year of age (Fig. $2 A$ ). However, no behavioral deficits were observed in these mice. Similarly, in line 70.48, a recognizable phenotype was also undetectable at 1 year of age.

The most remarkable phenotype manifested in line 70.61 .
70.42

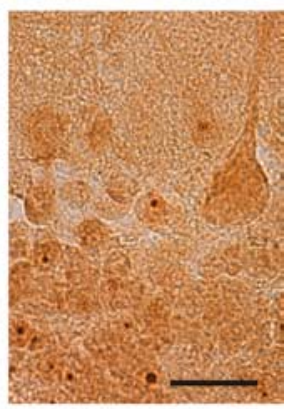

NES.34

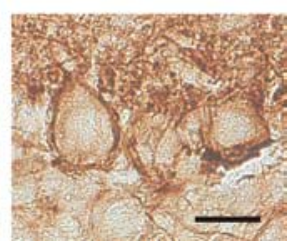

Mice from this line developed strong neurological symptoms with severe behavioral deficits starting at $6-8$ weeks of age with intense progression. These mice present with tremor, wide-based hindlimbs to stabilize the body in a resting position as well as markedly reduced activity and grooming, resulting in a disheveled appearance (Fig. 3D). Analysis of the footprint pattern of mildly affected mice ( $\sim 3$ months of age) revealed a minced gate with mild disturbances (Fig. 3A) and a significantly reduced distance between each step compared with wild-type mice (Fig. 3C). At the end stage of the disease, mice had a severely affected gait and were almost unable to walk (Fig. $3 A$ ). In addition, mice became almost completely inactive and were no longer capable of performing even the easiest behavioral tests (Fig. $3 B$ ). Transgenic mice from line 70.61 were easily discriminated from their negative littermates without genotyping because transgenic mice are remarkably smaller and weigh less than negative littermates of the same age (Fig. 3E). Immunohistochemical analysis of brain slices from line 70.61 showed a large number of both ataxin-3- and ubiquitin-positive neuronal intranuclear inclusion bodies in almost every examined brain region (Figs. $2 A, 4$ ).

Staining cerebellar sections of line 70.61 with an antibody against phosphorylated neurofilament revealed the occurrence of condensed or empty baskets around Purkinje cells (Fig. 2B). Electron microscopical analyses showed a striking shrinkage of $\sim 50-80 \%$ of Purkinje cells characterized by an increase of the electron density of the cytoplasm and the karyoplasm and by irregular alterations of the cytoplasmic and nuclear shapes. This shrinkage could clearly be distinguished from necrosis or apoptosis, and the nucleus was not pyknotic. In contrast to Purkinje cells, granule cells were not pathologically altered in this mouse line (Fig. $5 B$ ). Only $50 \%$ of mice survived their third month of age, and $>80 \%$ of the mice were dead after 6 months (Fig. $3 F$ ).

To check the suitability of our mouse model for additional tests, we analyzed selected parameters to assess potential restrictions: hearing measurements revealed no difference between transgenic SCA3 mice (line 70.61) and controls at 5-6 weeks of age. ABR thresholds on click stimuli and frequency-specific stimuli documented good hearing in both transgenic mice and controls. The good hearing thresholds were confirmed by the good function of the cochlear outer hair cells, as determined by the DPOAE threshold function and amplitude over the whole audio frequency range measured (supplemental Fig. 1, available at www.jneurosci.org as supplemental material). This result suggests the functional integrity of the structure and neuronal connections of the cochlea and the auditory brainstem.

In the transgenic R6/2 mouse model for Huntington's disease (Mangiarini et al., 1996), frequent occurrence of diabetes was reported (Hurlbert et al., 1999; Bjorkqvist et al., 2005). For this reason, we analyzed 18 standard laboratory parameters of the kidney, liver, pancreas, and muscle in the blood (data not shown). These analyses revealed no indication for organic malfunction or diabetes. 
We additionally analyzed the content of the neurotransmitters dopamine and serotonin in the striatum of transgenic SCA3 mice. Compared with controls, the content of dopamine was unchanged, whereas the content of its metabolites DOPAC and HVA were significantly reduced. For serotonin and its metabolite 5-HIAA, no significant differences were identified (Fig. 6A). However, the turnover rate of both dopamine and serotonin was significantly reduced (Fig. 6B).

Expansion of the polyglutamine length to 148 repeats worsens the phenotype in transgenic mice

We next generated three founders transgenic for full-length ataxin-3c with 148 CAG repeats. Regardless of the sex, all founders were severely affected, and only one mouse line (148.19) produced offspring. It is difficult to differentiate whether infertility of the founders was responsible for the lack of offspring or whether the severity of behavioral symptoms hindered the process of reproduction. Mice from mouse line 148.19 developed neurological deficits at 2 months, leading to death in their third month of age. Similar to the mouse model with 70 CAG repeats, the phenotype was characterized by tremor and wide-based hindlimbs, as well as markedly reduced motor and exploratory activity and grooming. However, symptoms appeared earlier than in mice with 70 CAG repeats, and the lifespan of mice with 148 CAG repeats was dramatically reduced; no mouse became older than 17 weeks (Fig. 3F). We often observed a failure to generate offspring in this line. In the brain of transgenic mice, as in the mouse model with 70 CAG repeats, numerous neuronal intranuclear inclusion bodies positive for ataxin-3 and ubiquitin were observed basically in all brain regions (see Fig. $10 \mathrm{~A}$ and data not shown).

\section{Nuclear export of ataxin-3 alleviates the phenotype}

In humans and in wild-type mice, ataxin-3 is found predominantly in the cytoplasm of neurons (Schmidt et al., 1998). Strikingly, in our transgenic SCA3 model as in affected patients, inclusion bodies form in the nucleus. For SCA3, it has not been shown yet in vivo whether the subcellular localization of ataxin-3 is critical for the development of symptoms.

For this reason, we attached an NES to the full-length ataxin-3 construct containing 148 CAG repeats. Tests in tissue culture confirmed an almost exclusive cytoplasmic localization of ataxin-3 (Fig. 7A). The nuclear export of ataxin-3 strongly facilitated the generation of transgenic mice. Of six transgenic founders, five stable mouse lines were established (Fig. $8 A$ ). In

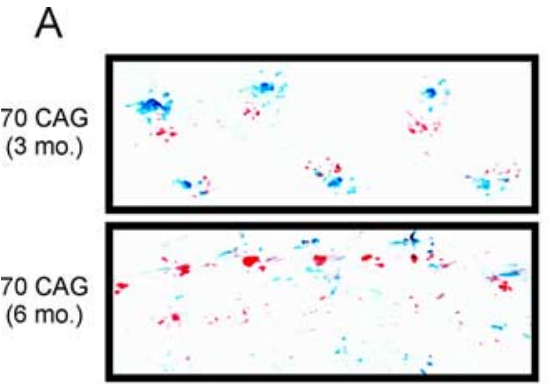

B Wild type

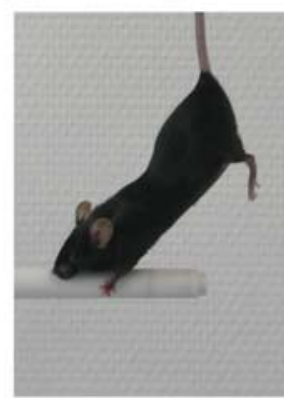

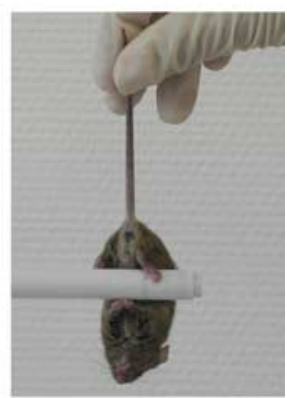

70 CAG

\section{C}

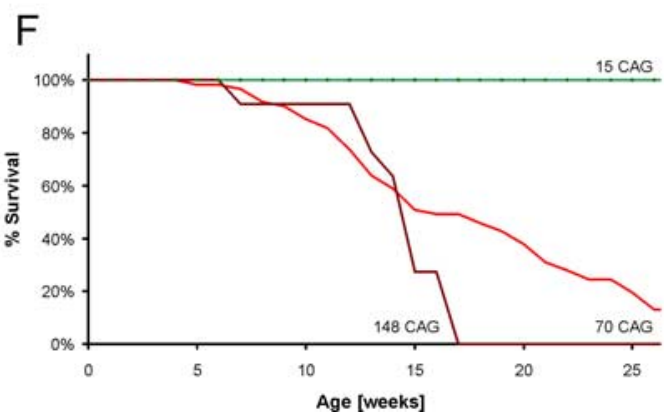

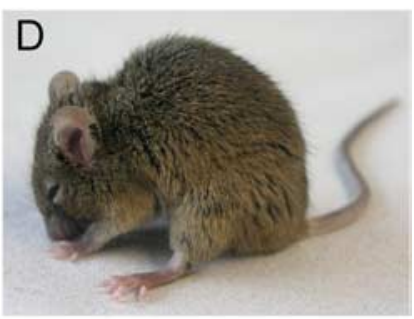

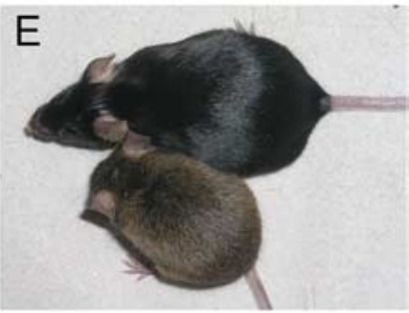

Figure 3. Analysis of transgenic SCA3 mice. $\boldsymbol{A}$, For gait analysis, forelimbs of mice were stained with red and hindlimbs with blue nontoxic paint. The gait of the young mouse with 70 CAG repeats (line 70.61) at 3 months of age is already slightly affected (see the minced gate), but the mouse is still able to walk. In the mouse at the end stage of the disease ( 6 months), the gate deteriorated and the mouse is almost incapable of walking. $\boldsymbol{B}$, The severe phenotype of transgenic SCA3 mice is conspicuous in the pen test. Control mice approaching a pen or rod from above grab for it and start walking on the pen. SCA3 mice (line 70.61, shown at 6 months of age), however, are not able to perform this task exhibiting a so-called clasping behavior. This test clearly demonstrates the disturbance of motor coordination caused by the expression of the expanded ataxin-3 transgenes. C, Statistical analysis of footprint pattern revealed a significant decrease of the distance between each step in mice carrying 70 CAG repeats compared with wild-type mice. The distance between each step is even more significantly reduced in mice with the 148 CAG repeat transgene $\left({ }^{* *} p<0.001\right)$. In addition, mice with 148 CAG (age, 10 weeks) perform significantly weaker than mice with 70 CAG repeats at 12 weeks of age ( $\left.{ }^{\#} p<0.001\right)$. D, Transgenic SCA3 mouse carrying 70 CAG repeats (line 70.61$)$. The wide-based hindlimbs, the hunchback, inactivity, and the disheveled appearance caused by reduced grooming are apparent. $\boldsymbol{E}$, Mice transgenic for ataxin-3 with 70 CAG repeats (the brown mouse) are significantly smaller than their negative littermates at the same age (black mouse). The difference in body size is also reflected in body weight. $\boldsymbol{F}$, Survival of transgenic SCA3 mice containing expanded CAG repeats as well as control mice (15 CAG repeats) was observed for $>6$ months. Only $50 \%$ of the SCA3 mice with 70 CAG repeats (line 70.61 ) survived for 4 months. After a period of 6 months, $>85 \%$ of these mice were dead, whereas no control mouse with 15 CAG repeats had died. The fact is even more apparent in mice carrying 148 CAG repeats (line 148.19): these mice die even earlier, and no mouse of this model survived $>17$ weeks. For each line, between 11 and 61 mice were included in this analysis.

one mouse line (line NES.34), male transgenic mice died at 6 weeks of age, whereas female transgenic mice survived for $>8$ months. Among the NES lines, this line expresses the transgene at the highest level. The cause of the reduced survival rate in males, however, could be attributable to integration effects of the transgene.

The phenotype of the other four mouse lines is dramatically milder than in mice without the NES: behavioral symptoms 


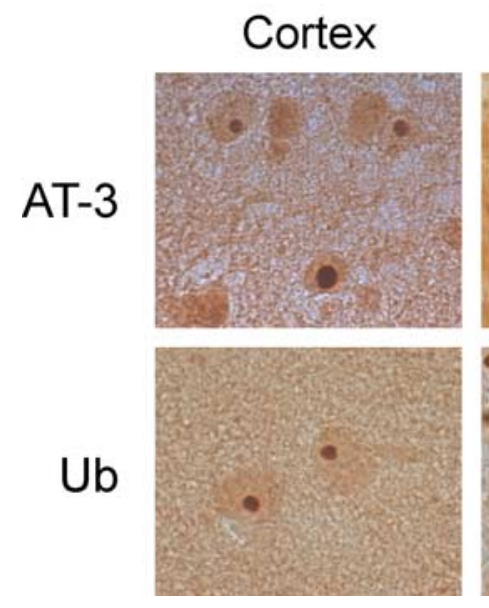

Hippocampus
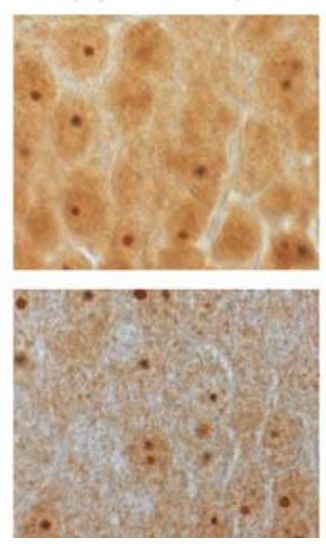

Pons
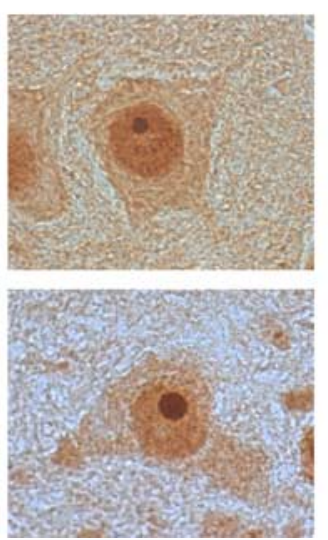

Cerebellum
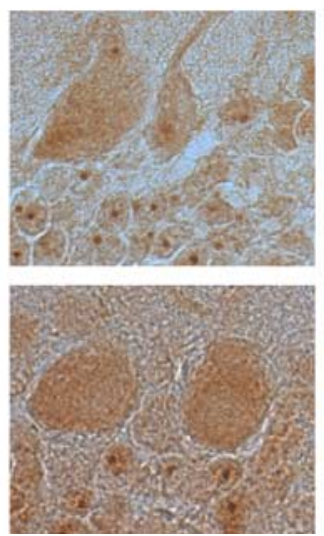

Cerebellar nuclei
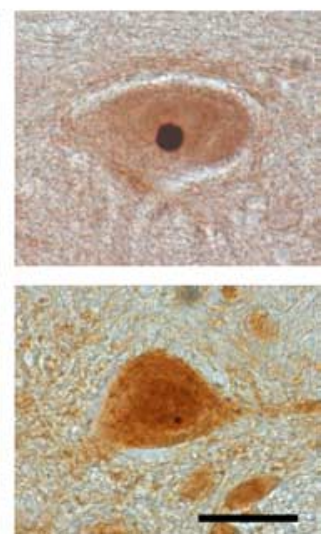

Figure 4. Expression of the expanded ataxin-3 transgene in different tissues. Tissue from different brain regions (cortex, hippocampus, pons, and cerebellum) of SCA3 transgenic mice with $70 \mathrm{CAG}$ repeats (line 70.61) at 3 months of age was stained immunohistochemically using antibodies against ataxin-3 (AT-3) and ubiquitin (Ub). In all examples, the large number of inclusion bodies is apparent. The inclusion bodies contain both ataxin-3 and ubiquitin. Scale bar, $20 \mu \mathrm{m}$.
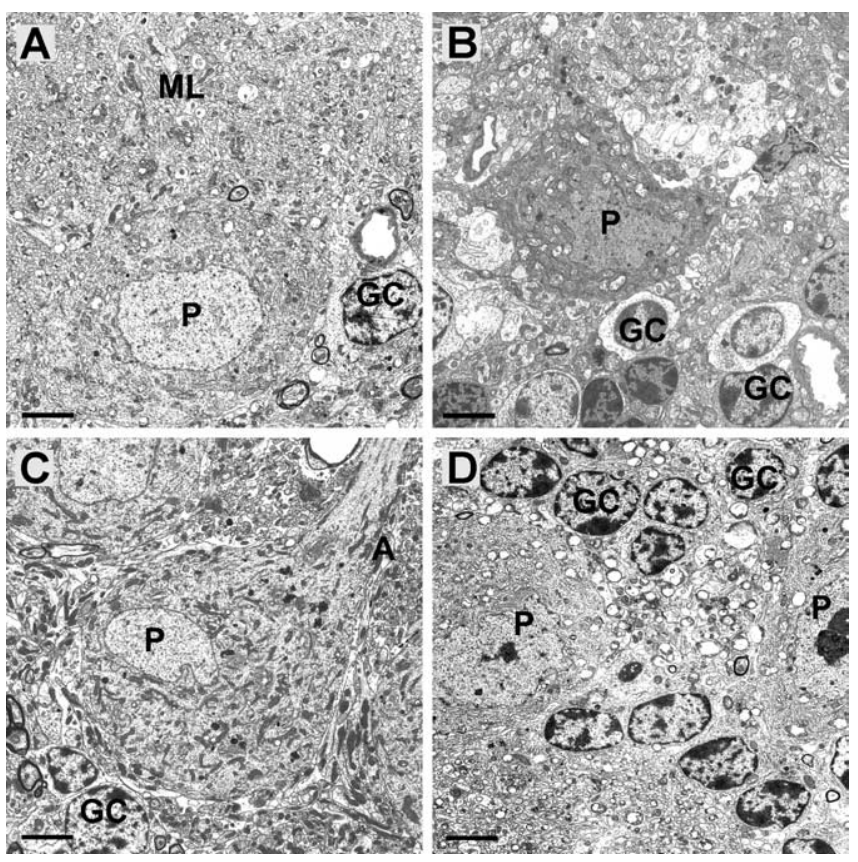

Figure 5. Electron microscopy of the cerebellum of transgenic SCA3 mice. $A$, Ultrathin section of the cerebellum of a control mouse with 15 CAG repeats at 3 months of age with overall normal findings: the Purkinje cell is characterized by a more or less round nucleus with granular chromatin and a high amount of rough endoplasmic reticulum. The molecular layer (ML) is formed of densely meshed axonal and dendritic neuronal as well as glial processes, and the extracellular space is small. The granule cells $(\mathrm{GC})$ have smaller nuclei than Purkinje cells $(\mathrm{P})$; however, the ratio between nucleus and cytoplasm is larger in granule cells compared with Purkinje cells. $B$, Ultrathin section of the cerebellum of a transgenic SCA3 mouse with 70 CAG repeats (line 70.61, 3 months of age). The striking pathological feature is the conspicuous shrinking of the Purkinje cells. The increase in the electron density of the cytoplasm and the karyoplasm and the irregular alteration of the cytoplasmic and nuclear shape is apparent. The granule cells $(\mathrm{GC})$ appear to be normal in this mouse. C, Ultrathin section of the cerebellum of the NES mouse model (line NES.42, 11 months of age). In this tissue, we were not able to identify pathological alterations, neither in granule cells nor in Purkinje cells. The molecular layer was unaltered. D, Ultrathin section of the cerebellum of the NLS mouse model (line NLS.28, 11 months of age). The GCs mainly grouped around Purkinje cells appear to be normal. The Ps appear slightly shrunken and the nuclei slightly indented. However, these alterations are not as prominent as in the model without localization signals (Fig. 5B). A, Astrocyte. Scale bars, $5 \mu \mathrm{m}$.
A
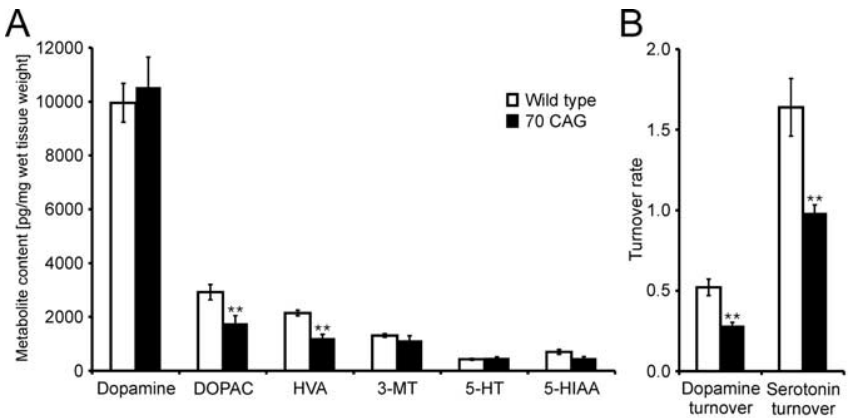

Figure 6. Content of neurotransmitters and their metabolites in SCA3 transgenic mice (line 70.61) and controls. $\boldsymbol{A}$, The content of neurotransmitters was determined using HPLC and is presented in picograms of substance per $1 \mathrm{mg}$ of wet tissue. Each data point represents the mean ( \pm SEM) of five male mice at 3 months of age. In mice transgenic for ataxin- 3 with 70 CAG repeats, the content of both DOPAC $(p<0.05)$ and HVA $(p<0.005)$ was significantly reduced. $\boldsymbol{B}$, Dopamine and serotonin turnover rates were calculated according to Masilamoni et al. (2005). The turnover rates of both dopamine $(p<0.005)$ and serotonin $(p<0.05)$ were significantly reduced in our SCA3 mouse model. 3-MT, 3-Methoxytyramine. Dopamine turnover $=($ DOPAC + HVA $) /$ dopamine. Serotonin turnover $=(5-H I A A / 5-H T)$.

are mild (Fig. 9) or completely missing, and the life expectancy of these mice seems to be practically unchanged. Immunohistochemically, only a very low number of inclusion bodies and, compared with the model without NES, a significant decrease of the number of inclusions were observed in all analyzed brain regions (Fig. 10). We did not find aggregates in the cytoplasm of neurons in the transgenic NES mouse lines (Fig. $10 A$ ) or in cells overexpressing NES-tagged ataxin-3 with 148 CAG repeats (Fig. $7 A$ ), demonstrating that the nuclear localization of ataxin-3 is a prerequisite for aggregate formation. In addition, on the electron microscopical level, no pathological alterations were found in the layers of granule cells, Purkinje cells, or in the molecular layer (Fig. 5C). We thus conclude that restraining ataxin-3 from entering the nucleus using an NES essentially diminished and delayed the pathogenic effects of the expanded polyglutamine repeat.

\section{Nuclear localization of ataxin-3 is essential for neurodegeneration}

We also investigated the consequences of targeting ataxin-3 into the nucleus using a nuclear localization signal (NLS). An attach- 
ment of the NLS taken from the SV40 large $\mathrm{T}$ antigen (Kalderon et al., 1984) to ataxin-3 led to nuclear localization of ataxin-3 in cell culture (Fig. $7 A$ ). In vivo, only three stable mouse lines were established from a total of eight transgenic founders (Fig. $8 \mathrm{~B}$ ). These founders were severely affected by the same behavioral deficits already observed in the mice with the untagged transgene, but even earlier and more severe (Fig. 9). Using Western blotting, we were only able to detect a faint band of transgenic ataxin-3 in some mouse lines (Fig. 8B), whereas NLStagged ataxin- 3 was easily detected in tissue culture samples (Fig. $7 B$ ). In the other NLS mouse lines, however, we were not capable to detect soluble ataxin-3 in Western blots even using different protein-

isolation protocols presumably because all transgenic protein was recruited into aggregates. We verified the expression of the transgene in selected mouse lines using quantitative reverse transcription-PCR, confirming that the transgene with NLS is expressed. We observed that the expression in the NLS model is up to eight times lower than in mouse lines with NES, suggesting that mice with high expression of the NLS-tagged transgene are not viable (data not shown).

Immunohistochemically, NLS mice were characterized by a very high number of intranuclear inclusion bodies in almost every analyzed brain area (Fig. 10A). The percentage of cells with inclusion bodies was significantly increased in transgenic mice with NLS compared with mice containing ataxin-3 with an NES and with ataxin-3 without localization signals (Fig. 10B). We confirmed, by comparing mouse lines NLS.28 and NES.17, that this observed difference is solely caused by nuclear export and import and is independent of transgene expression strength. Although the transgene is expressed eight times stronger in lines NES.17 than in line NLS.28, line NLS.28 has more aggregates and a stronger phenotype (data not shown).

In contrast to the model with $70 \mathrm{CAG}$ repeats, the formation of condensed or empty neurofilament-positive baskets about Purkinje cells was not so marked (Fig. $2 B$ ). However, electron microscopic analyses also revealed slightly shrunken Purkinje cells with increased electron density of the cytoplasm even if the ratio of shrunken cells $(\sim 10 \%)$ was not as high as in the models without NLS (Fig. 5D). Unexpectedly, it was striking to observe some swollen Purkinje cell dendrites within the molecular layer (data not shown). Of 20 Purkinje cells, $\sim 3-5$ had swollen dendritic profiles. Together, all analyzed aspects of the phenotype (lifespan, severity of behavioral deficits, the number of inclusion bodies, and neuropathology) clearly demonstrate that nuclear localization of ataxin-3 aggravates the phenotype in transgenic mice, whereas nuclear export of ataxin-3 remarkably reduces the phenotype.

\section{Discussion}

The role of the subcellular localization of aberrant proteins in polyglutamine diseases is still a matter of debate. There is clear evidence for the nucleus as the most sensitive site of neurotoxicity in SCA1 (Klement et al., 1998), but there are other reports of a contribution of cytoplasmically localized aberrant protein in Huntington's disease (Hackam et al., 1999; Hodgson et al., 1999; Trushina et al., 2003). In addition, except for transgenic HD

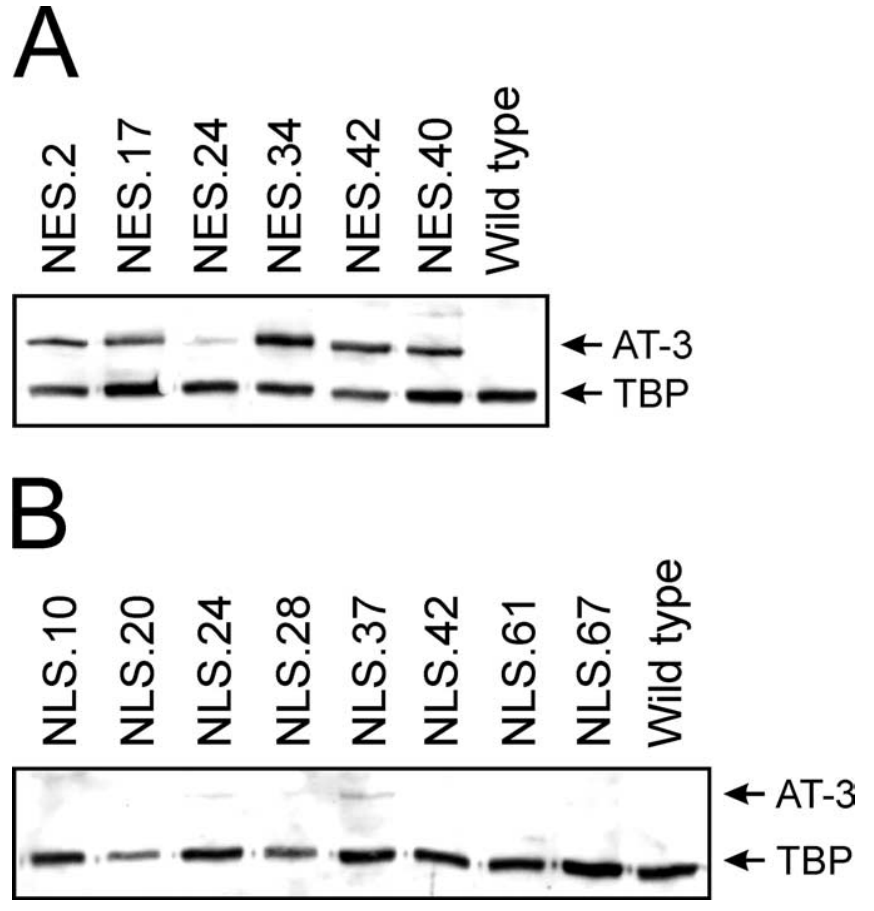

Figure 8. Comparison of transgenic mouse lines containing NLS or NES-tagged ataxin-3 (AT-3) with 148 CAG repeats. Brains of transgenic mice were lysed, and the proteins were analyzed by Western blotting using the $1(2$ antibody against expanded polyglutamine repeats. $\boldsymbol{A}, \boldsymbol{B}$, Whereas the transgene is detectable in mice carrying an NES $(\boldsymbol{A} ; \mathrm{AT}-3)$, only a very faint band is visible in mice carrying an NLS $(\boldsymbol{B})$, possibly because of the fact that all of the protein is recruited to protein aggregates. TBP marks the TATA binding protein, which is codetected when using the $1 \mathrm{C} 2$ antibody, because TBP was used for the generation of the antibody. Ages of analyzed mice: up to 5 months (NES.2, NES.17, NES.24, NES.34, NES.42, NLS.10, NLS.20, NLS.24, NLS.28, and NLS.37) and 7 months (NES.40, NLS.42, NLS.61, and NLS.67). Age differs because affected founders generating no offspring were kept until the end stage of the disease.

models, the influence of the CAG repeat length on the phenotype has not been explored in transgenic models of SCA yet.

Here, we generated a series of transgenic mouse models of SCA3 to investigate the influence of repeat length and subcellular localization of the protein on the phenotype and neuropathology. We provide evidence that overexpression of full-length wild-type ataxin-3c with 15 CAG repeats in mice does not cause neurological deficits or a phenotype, possibly because of its ubiquitinprotease activity (Burnett et al., 2003). However, transgenic mice carrying $70 \mathrm{CAG}$ repeats revealed a severe and rapidly progressive 


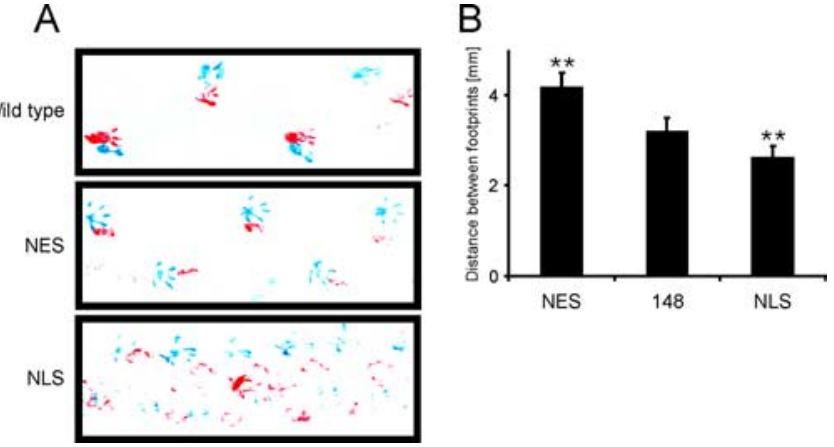

Figure 9. Footprint pattern of transgenic mice containing ataxin-3 with 148 CAG repeats supplemented with either an NES or NLS compared with a wild-type mouse. $A$, The clear differences in footprint pattern are apparent. Compared with the wild-type mouse, the distance between each step is reduced in the NES mouse (line NES.24, 11 months), and the mouse is walking on tiptoe but is still able to walk. The gait of the NLS mouse (line NLS.10) at the same age, however, is severely affected, and the difficulty of this mouse to walk is apparent. $\boldsymbol{B}$, The footprint patterns were compared and measured for the distance between each step. A reduced distance of footprints reflects a minced gait. This disturbance is significantly reduced by the NES $(p<0.001)$ and significantly enhanced by the NLS $(p<0.001)$, resulting in an extended and reduced distance between each step, respectively. Shown is the mean of all available respective mouse lines at $10-12$ months of age.

phenotype displaying a large number of NIIs. As with human SCA3 patients, these mice die prematurely. In some lines, we observed a milder phenotype with slower progression, which might be attributable to weaker expression of the transgene or lack of expression in specific brain regions.

Analyzing the neurotransmitter content in the disease model with 70 CAG repeats, we noticed a significant reduction of the dopamine metabolites DOPAC and HVA as well as of the turnover rate of both dopamine and serotonin compared with wildtype littermates. A reduction of dopamine metabolites was also observed in human SCA3 cases (Higgins et al., 1996), as well as in transgenic mouse models of HD (Reynolds et al., 1999; Duan et al., 2004) and HD patients (Reynolds and Garrett, 1986). Interestingly, normalization of observed serotonin deficits in HD mice delayed neurodegeneration (Reynolds et al., 1999; Duan et al., 2004). Our data indicate that a similar approach might also be considered for our SCA3 model. Also, these data need to be validated in human SCA3 patients to further support the validity of the mouse line as an appropriate disease model for preclinical treatment studies. In this respect, it was important to rule out any metabolic disturbances like diabetes in our mouse model, as reported previously for a mouse model of HD (Hurlbert et al., 1999; Bjorkqvist et al., 2005).

Here, we demonstrate that both the size of the expanded CAG repeat length and the level of transgene expression are of major importance for disease onset and disease progression in mice. Mice with reduced expression of ataxin-3 with 70 CAG repeats develop a milder phenotype than lines with a stronger expression. Furthermore, transgenic mice with 148 CAG repeats merely survive the first months and have major problems to produce offspring, whereas mice with stronger expression of this transgene die very early without producing any offspring.

To date, three different mouse models of SCA3 have been described: Ikeda et al. (1996) used the Purkinje-cell-specific promoter for the generation of their mouse model. Surprisingly, using a full-length ataxin-3 construct containing 79 CAG repeats, they did not find any phenotype in their mice. Only after severe truncation of ataxin-3, neurological deficits were observed. Thus, this model proves neurotoxicity of polyQ expansions but not of an aberrant ataxin-3 protein. Cemal et al. (2002) used a YAC construct spanning the human SCA3 locus containing up to 84 CAG repeats in the MJD1 gene under the control of its endogenous control elements. These mice developed a neurological SCA3-like phenotype with very slow progression, possibly because of the fact that human control elements might behave slightly different in mice, resulting in a weaker expression of the transgene. The most recent model described by Goti et al. (2004) contained the full-length MJD1 gene (71 CAG repeats) under the control of the prion protein promoter. However, only homozygous mice developed symptoms, and these mice cannot be used for additional breeding because of infertility.

For our mouse model, we used a slightly different part of the prion protein promoter and a different isoform of ataxin-3. Based on our current knowledge, it seems to be doubtful that, as in our mice, the ataxin-3c isoform with an alternative $\mathrm{C}$ terminus, instead of the MJD1a isoform (Goto et al., 1997), is responsible for the different progression of the phenotype between the two studies. It is more likely that the part of the prion protein promoter that we selected for our construct led to a stronger and therefore more sufficient expression of the transgene, resulting in severely affected mice even in the heterozygous state. The construct of Goti et al. (2004) contained $5.5 \mathrm{~kb}$ upstream of exon 1 of the murine prion protein gene. Our construct comprises just 1.1 $\mathrm{kb}$ of upstream sequence. However, this shorter fragment proved to contain enough control elements for sufficient gene expression in tissue culture (Baybutt and Manson, 1997) and in practically any brain region in transgenic mice (Gispert et al., 2003). Therefore, silencing Prp promoter control elements in the larger construct might have weakened the expression of ataxin-3 in the mouse model of Goti et al. (2004).

To assess the role of intracellular localization of expanded ataxin-3, we used a construct with 148 polyglutamine repeats and attached a nuclear localization or an export signal to its $\mathrm{C}$ terminus. Mice transgenic for the construct with an NES exhibit a very mild phenotype with only a very low number of NIIs, a footprint pattern revealing only mild motor deficits, and an unaffected lifespan. However, mice expressing NES-tagged ataxin-3 were not completely free of symptoms, and NIIs were not completely absent. One explanation might be that the nuclear export of ataxin-3 in mice was not completely sufficient and that a small amount of ataxin-3 remained in the nucleus. Interestingly, the NES does not only suppress the formation of NIIs almost completely, it also seems to prevent the aggregation of ataxin-3. In SCA2 (Huynh et al., 2000), SCA6 (Ishikawa et al., 1999), and Huntington's disease (DiFiglia et al., 1997; Hackam et al., 1999; Peters et al., 1999), cytoplasmic aggregates could be identified. As in human SCA3 patients (Schmidt et al., 1998), cytoplasmic protein aggregates were not identified in our SCA3 mice, neither with anti-ataxin-3 nor with anti-ubiquitin antibodies. Therefore, keeping the expanded polyglutamine repeats in the cytoplasm might delay protein aggregation, giving easier and longer access of the toxic protein to the protein degradation machinery.

In contrast to the nuclear export, nuclear localization of ataxin-3 with 148 polyglutamine repeats accelerated and intensified the phenotype of transgenic mice even further. The number of aggregates was significantly increased, and these mice were so severely affected that in most cases they were not able to reproduce before their premature death. These results are consistent with observations in SCA1 and DRPLA in which nuclear localization accelerates the formation of polyQ aggregates (Klement et al., 1998; Toyoshima et al., 2002) and underline the importance of nuclear localization of ataxin-3 and other proteins with poly- 
glutamine expansion for the pathogenesis and the onset and progression of symptoms.

The role of nuclear localization in polyglutamine diseases was the subject of many different studies. However, we present here the first in vivo evidence regarding the role of nuclear localization and export in SCA3. A recent study by Benn et al. (2005) analyzed the effect of nuclear or cytoplasmic localization of the $\mathrm{N}$-terminal part of huntingtin in transgenic mice. In contrast to our results in SCA3, they observed that even huntingtin fragments coupled to a nuclear export signal cause a severe phenotype with cytoplasmic aggregates. This observation might indicate that the pathogenic processes mostly differ between HD and SCA3. Additionally, the nuclear export of expanded huntingtin was not completely sufficient possibly because of the use of a different type of nuclear export signal. Benn et al. (2005) used the NES of MAPKK (mitogen-activated protein kinase kinase); in our study, the NES of PKI was used. Therefore, securing a sufficient nuclear export of expanded huntingtin might also slow down the pathogenic process in HD as we demonstrated for SCA3 in the present study.

Together, we not only present new mouse models of SCA3 with a strong phenotype, rapid progression, and premature death, which we expect to be the ideal model for future therapeutic studies. We demonstrate in vivo that the severity of symptoms in SCA3 is linked to the number of expanded polyglutamine repeats. Also, nuclear localization of ataxin-3 aggravates the formation of protein aggregates and the development of a phenotype, whereas nuclear export of the protein results in a reduced number of NIIs and a much milder phenotype. Depending on the effectiveness of this nuclear transport, the intensity of symptoms and the severity of the phenotype are emerging. The different mouse models generated in this study will be a valuable tool to study the effects of nuclear transport in SCA3.

\section{References}

Albrecht M, Golatta M, Wüllner U, Lengauer T (2004) Structural and functional analysis of ataxin-2 and ataxin-3. Eur J Biochem 271:3155-3170.

Baybutt H, Manson J (1997) Characterisation of two promoters for prion protein (PrP) gene expression in neuronal cells. Gene 184:125-131.

Benn CL, Landles C, Li H, Strand AD, Woodman B, Sathasivam K, Li SH, Ghazi-Noori S, Hockly E, Faruque SM, Cha JH, Sharpe PT, Olson JM, Li XJ, Bates GP (2005) Contribution of nuclear and extranuclear polyQ to neurological phenotypes in mouse models of Huntington's disease. Hum Mol Genet 14:3065-3078.

Bjorkqvist M, Fex M, Renstrom E, Wierup N, Petersen A, Gil J, Bacos K, Popovic N, Li JY, Sundler F, Brundin P, Mulder H (2005) The R6/2 transgenic mouse model of Huntington's disease develops diabetes due to deficient beta-cell mass and exocytosis. Hum Mol Genet 14:565-574.

Bradford MM (1976) A rapid and sensitive method for the quantitation of respectively.

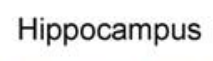

Pons
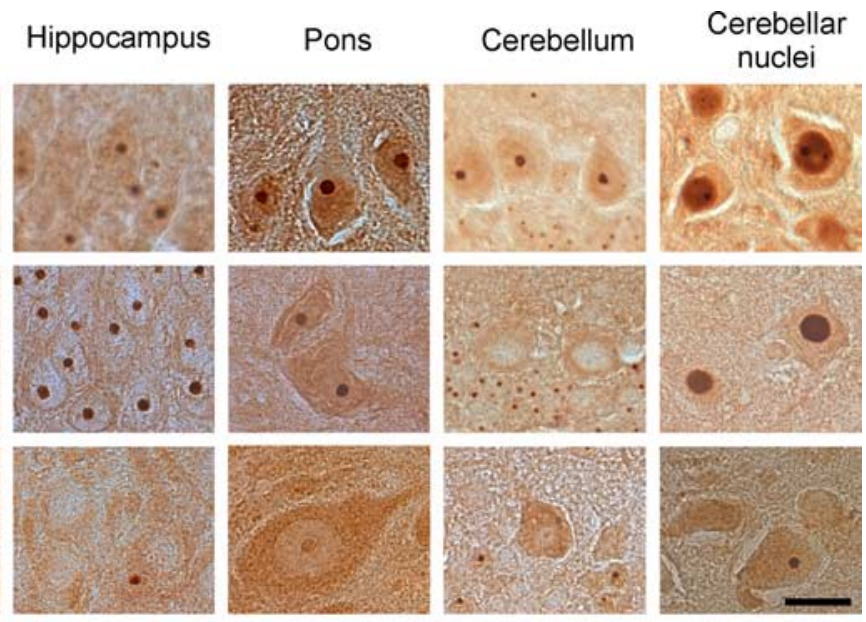

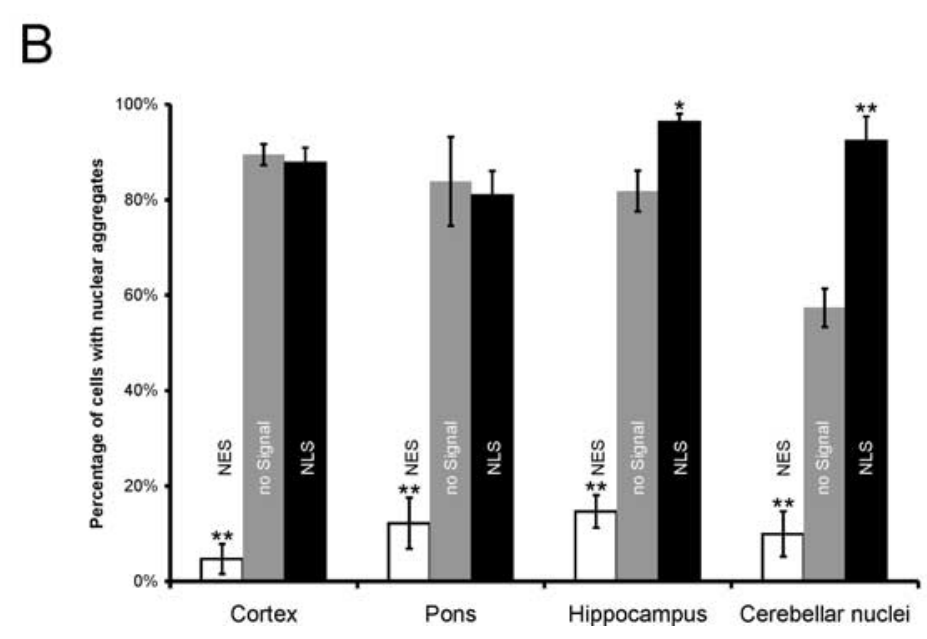

Figure 10. Nuclear export of expanded ataxin-3 prevents the formation of intranuclear inclusion bodies. A, Brains of mice transgenic for ataxin-3 constructs containing 148 CAG repeats were analyzed immunohistochemically using an anti-ataxin-3 antibody for the formation of intranuclear inclusion bodies. The transgene is tagged either with or without nuclear localization or identified in mice conta increases the number of inclusion bodies. Scale bar, $20 \mu \mathrm{m}$. B. For each construct (with or without a localization signal; NLS or NES), one exemplary mouse line was analyzed for the percentage of neurons containing inclusion bodies. Four brain regions (pons, cerebellar nuclei, hippocampus, and cortex) were compared. The presented data reflect the mean of up to 10 randomly selected (n) number of inclusion bodies $\left.{ }^{* *} p<0.001\right)$. A, B , Data for line NLS.37 at 4 months of age and line NES. 17 at 5 months of age,

microgram quantities of protein utilizing the principle of protein-dye binding. Anal Biochem 72:248-254.

Burnett B, Li F, Pittman RN (2003) The polyglutamine neurodegenerative protein ataxin-3 binds polyubiquitylated proteins and has ubiquitin protease activity. Hum Mol Genet 12:3195-3205.

Carnicero E, Zelarayan LC, Ruttiger L, Knipper M, Alvarez Y, Alonso MT, Schimmang T (2004) Differential roles of fibroblast growth factor-2 during development and maintenance of auditory sensory epithelia. J Neurosci Res 77:787-797.

Cemal CK, Carroll CJ, Lawrence L, Lowrie MB, Ruddle P, Al-Mahdawi S, King RH, Pook MA, Huxley C, Chamberlain S (2002) YAC transgenic mice carrying pathological alleles of the MJD1 locus exhibit a mild and slowly progressive cerebellar deficit. Hum Mol Genet 11:1075-1094.

Cooper JK, Schilling G, Peters MF, Herring WJ, Sharp AH, Kaminsky Z, Masone J, Khan FA, Delanoy M, Borchelt DR, Dawson VL, Dawson TM, Ross CA (1998) Truncated N-terminal fragments of huntingtin with expanded glutamine repeats form nuclear and cytoplasmic aggregates in cell culture. Hum Mol Genet 7:783-790.

DiFiglia M, Sapp E, Chase KO, Davies SW, Bates GP, Vonsattel JP, Aronin N 
(1997) Aggregation of huntingtin in neuronal intranuclear inclusions and dystrophic neurites in brain. Science 277:1990-1993.

Duan W, Guo Z, Jiang H, Ladenheim B, Xu X, Cadet JL, Mattson MP (2004) Paroxetine retards disease onset and progression in Huntingtin mutant mice. Ann Neurol 55:590-594.

Dürr A, Stevanin G, Cancel G, Duyckaerts C, Abbas N, Didierjean O, Chneiweiss H, Benomar A, Lyon CO, Julien J, Serdaru M, Penet C, Agid Y, Brice A (1996) Spinocerebellar ataxia 3 and Machado-Joseph disease: clinical, molecular, and neuropathological features. Ann Neurol 39:490-499.

Gispert S, Del Turco D, Garrett L, Chen A, Bernard DJ, Hamm-Clement J, Korf HW, Deller T, Braak H, Auburger G, Nussbaum RL (2003) Transgenic mice expressing mutant A53T human alpha-synuclein show neuronal dysfunction in the absence of aggregate formation. Mol Cell Neurosci 24:419-429.

Goti D, Katzen SM, Mez J, Kurtis N, Kiluk J, Ben-Haiem L, Jenkins NA, Copeland NG, Kakizuka A, Sharp AH, Ross CA, Mouton PR, Colomer V (2004) A mutant ataxin-3 putative-cleavage fragment in brains of Machado-Joseph disease patients and transgenic mice is cytotoxic above a critical concentration. J Neurosci 24:10266-10279.

Goto J, Watanabe M, Ichikawa Y, Yee SB, Ihara N, Endo K, Igarashi S, Takiyama Y, Gaspar C, Maciel P, Tsuji S, Rouleau GA, Kanazawa I (1997) Machado-Joseph disease gene products carrying different carboxyl termini. Neurosci Res 28:373-377.

Green EC, Gkoutos GV, Lad HV, Blake A, Weekes J, Hancock JM (2005) EMPReSS: Eur mouse phenotyping resource for standardized screens. Bioinformatics 21:2930-2931.

Hackam AS, Singaraja R, Zhang T, Gan L, Hayden MR (1999) In vitro evidence for both the nucleus and cytoplasm as subcellular sites of pathogenesis in Huntington's disease. Hum Mol Genet 8:25-33.

Higgins JJ, Harvey-White JD, Nee LE, Colli MJ, Grossi TA, Kopin IJ (1996) Brain MRI, lumbar CSF monoamine concentrations, and clinical descriptors of patients with spinocerebellar ataxia mutations. J Neurol Neurosurg Psychiatry 61:591-595.

Hodgson JG, Agopyan N, Gutekunst CA, Leavitt BR, LePiane F, Singaraja R, Smith DJ, Bissada N, McCutcheon K, Nasir J, Jamot L, Li XJ, Stevens ME, Rosemond E, Roder JC, Phillips AG, Rubin EM, Hersch SM, Hayden MR (1999) A YAC mouse model for Huntington's disease with full-length mutant huntingtin, cytoplasmic toxicity, and selective striatal neurodegeneration. Neuron 23:181-192.

Hurlbert MS, Zhou W, Wasmeier C, Kaddis FG, Hutton JC, Freed CR (1999) Mice transgenic for an expanded CAG repeat in the Huntington's disease gene develop diabetes. Diabetes 48:649-651.

Huynh DP, Figueroa K, Hoang N, Pulst SM (2000) Nuclear localization or inclusion body formation of ataxin-2 are not necessary for SCA2 pathogenesis in mouse or human. Nat Genet 26:44-50.

Ikeda H, Yamaguchi M, Sugai S, Aze Y, Narumiya S, Kakizuka A (1996) Expanded polyglutamine in the Machado-Joseph disease protein induces cell death in vitro and in vivo. Nat Genet 13:196-202.

Ishikawa K, Fujigasaki H, Saegusa H, Ohwada K, Fujita T, Iwamoto H, Komatsuzaki Y, Toru S, Toriyama H, Watanabe M, Ohkoshi N, Shoji S, Kanazawa I, Tanabe T, Mizusawa H (1999) Abundant expression and cytoplasmic aggregations of $\alpha 1 \mathrm{~A}$ voltage-dependent calcium channel protein associated with neurodegeneration in spinocerebellar ataxia type 6. Hum Mol Genet 8:1185-1189.

Kalderon D, Roberts BL, Richardson WD, Smith AE (1984) A short amino acid sequence able to specify nuclear location. Cell 39:499-509.

Kawaguchi Y, Okamoto T, Taniwaki M, Aizawa M, Inoue M, Katayama S, Kawakami H, Nakamura S, Nishimura M, Akiguchi I, Kimura J, Narumiya S, Kakizuka A (1994) CAG expansions in a novel gene for Machado-Joseph disease at chromosome 14q32.1. Nat Genet 8:221-228.

Kaytor MD, Duvick LA, Skinner PJ, Koob MD, Ranum LP, Orr HT (1999) Nuclear localization of the spinocerebellar ataxia type 7 protein, ataxin-7. Hum Mol Genet 8:1657-1664.

Kilpatrick IC, Jones MW, Phillipson OT (1986) A semiautomated analysis method for catecholamines, indoleamines, and some prominent metabolites in microdissected regions of the nervous system: an isocratic HPLC technique employing coulometric detection and minimal sample preparation. J Neurochem 46:1865-1876.

Klement IA, Skinner PJ, Kaytor MD, Yi H, Hersch SM, Clark HB, Zoghbi HY, Orr HT (1998) Ataxin-1 nuclear localization and aggregation: role in polyglutamine-induced disease in SCA1 transgenic mice. Cell 95:41-53.

Knipper M, Zinn C, Maier H, Praetorius M, Rohbock K, Kopschall I, Zim- mermann U (2000) Thyroid hormone deficiency before the onset of hearing causes irreversible damage to peripheral and central auditory systems. J Neurophysiol 83:3101-3112.

Laccone F (2002) A fast polymerase chain reaction-mediated strategy for introducing repeat expansions into CAG-repeat containing genes. Methods Mol Biol 192:217-223.

Laemmli UK (1970) Cleavage of structural proteins during assembly of the head of bacteriophage T4. Nature 227:680-685.

Lundkvist A, Reichenbach A, Betsholtz C, Carmeliet P, Wolburg H, Pekny M (2004) Under stress, the absence of intermediate filaments from Muller cells in the retina has structural and functional consequences. J Cell Sci 117:3481-3488.

Mangiarini L, Sathasivam K, Seller M, Cozens B, Harper A, Hetherington C, Lawton M, Trottier Y, Lehrach H, Davies SW, Bates GP (1996) Exon 1 of the HD gene with an expanded CAG repeat is sufficient to cause a progressive neurological phenotype in transgenic mice. Cell 87:493-506.

Masilamoni JG, Vignesh S, Kirubagaran R, Jesudason EP, Jayakumar R (2005) The neuroprotective efficacy of alpha-crystallin against acute inflammation in mice. Brain Res Bull 67:235-241.

Nakamura K, Jeong SY, Uchihara T, Anno M, Nagashima K, Nagashima T, Ikeda S, Tsuji S, Kanazawa I (2001) SCA17, a novel autosomal dominant cerebellar ataxia caused by an expanded polyglutamine in TATA-binding protein. Hum Mol Genet 10:1441-1448.

Paulson HL, Das SS, Crino PB, Perez MK, Patel SC, Gotsdiner D, Fischbeck KH, Pittman RN (1997a) Machado-Joseph disease gene product is a cytoplasmic protein widely expressed in brain. Ann Neurol 41:453-462.

Paulson HL, Perez MK, Trottier Y, Trojanowski JQ, Subramony SH, Das SS, Vig P, Mandel JL, Fischbeck KH, Pittman RN (1997b) Intranuclear inclusions of expanded polyglutamine protein in spinocerebellar ataxia type 3. Neuron 19:333-344.

Peters MF, Nucifora Jr FC, Kushi J, Seaman HC, Cooper JK, Herring WJ, Dawson VL, Dawson TM, Ross CA (1999) Nuclear targeting of mutant Huntingtin increases toxicity. Mol Cell Neurosci 14:121-128.

Reynolds GP, Garrett NJ (1986) Striatal dopamine and homovanillic acid in Huntington's disease. J Neural Transm 65:151-155.

Reynolds GP, Dalton CF, Tillery CL, Mangiarini L, Davies SW, Bates GP (1999) Brain neurotransmitter deficits in mice transgenic for the Huntington's disease mutation. J Neurochem 72:1773-1776.

Rogers DC, Fisher EM, Brown SD, Peters J, Hunter AJ, Martin JE (1997) Behavioral and functional analysis of mouse phenotype: SHIRPA, a proposed protocol for comprehensive phenotype assessment. Mamm Genome 8:711-713.

Schimmang T, Tan J, Muller M, Zimmermann U, Rohbock K, Kopschall I, Limberger A, Minichiello L, Knipper M (2003) Lack of Bdnf and TrkB signalling in the postnatal cochlea leads to a spatial reshaping of innervation along the tonotopic axis and hearing loss. Development 130:4741-4750.

Schmidt T, Landwehrmeyer GB, Schmitt I, Trottier Y, Auburger G, Laccone F, Klockgether T, Volpel M, Epplen JT, Schols L, Riess O (1998) An isoform of ataxin-3 accumulates in the nucleus of neuronal cells in affected brain regions of SCA3 patients. Brain Pathol 8:669-679.

Schmidt T, Lindenberg KS, Krebs A, Schols L, Laccone F, Herms J, Rechsteiner M, Riess O, Landwehrmeyer GB (2002) Protein surveillance machinery in brains with spinocerebellar ataxia type 3: redistribution and differential recruitment of $26 \mathrm{~S}$ proteasome subunits and chaperones to neuronal intranuclear inclusions. Ann Neurol 51:302-310.

Schmitt I, Brattig T, Gossen M, Riess O (1997) Characterization of the rat spinocerebellar ataxia type 3 gene. Neurogenetics 1:103-112.

Schöls L, Gispert S, Vorgerd M, Menezes Vieira-Saecker AM, Blanke P, Auburger G, Amoiridis G, Meves S, Epplen JT, Przuntek H, Pulst SM, Riess O (1997) Spinocerebellar ataxia type 2. Genotype and phenotype in German kindreds. Arch Neurol 54:1073-1080.

Schöls L, Bauer P, Schmidt T, Schulte T, Riess O (2004) Autosomal dominant cerebellar ataxias: clinical features, genetics, and pathogenesis. Lancet Neurol 3:291-304.

Servadio A, Koshy B, Armstrong D, Antalffy B, Orr HT, Zoghbi HY (1995) Expression analysis of the ataxin-1 protein in tissues from normal and spinocerebellar ataxia type 1 individuals. Nat Genet 10:94-98.

Srinivasan J, Schmidt WJ (2004) Functional recovery of locus coeruleus noradrenergic neurons after DSP-4 lesion: effects on dopamine levels and neuroleptic induced-parkinsonian symptoms in rats. J Neural Transm 111:13-26. 
Tait D, Riccio M, Sittler A, Scherzinger E, Santi S, Ognibene A, Maraldi NM, Lehrach H, Wanker EE (1998) Ataxin-3 is transported into the nucleus and associates with the nuclear matrix. Hum Mol Genet 7:991-997.

Takiyama Y, Oyanagi S, Kawashima S, Sakamoto H, Saito K, Yoshida M, Tsuji S, Mizuno Y, Nishizawa M (1994) A clinical and pathologic study of a large Japanese family with Machado-Joseph disease tightly linked to the DNA markers on chromosome 14q. Neurology 44:1302-1308.

Toyoshima I, Sugawara M, Kato K, Wada C, Shimohata T, Koide R, Onodera O, Tsuji S (2002) Time course of polyglutamine aggregate body formation and cell death: enhanced growth in nucleus and an interval for cell death. J Neurosci Res 68:442-448.

Trottier Y, Cancel G, An-Gourfinkel I, Lutz Y, Weber C, Brice A, Hirsch E, Mandel JL (1998) Heterogeneous intracellular localization and expression of ataxin-3. Neurobiol Dis 5:335-347.
Trushina E, Heldebrant MP, Perez-Terzic CM, Bortolon R, Kovtun IV, Badger II JD, Terzic A, Estevez A, Windebank AJ, Dyer RB, Yao J, McMurray CT (2003) Microtubule destabilization and nuclear entry are sequential steps leading to toxicity in Huntington's disease. Proc Natl Acad Sci USA 100:12171-12176.

van de Warrenburg BP, Sinke RJ, Verschuuren-Bemelmans CC, Scheffer H, Brunt ER, Ippel PF, Maat-Kievit JA, Dooijes D, Notermans NC, Lindhout D, Knoers NV, Kremer HP (2002) Spinocerebellar ataxias in The Netherlands: prevalence and age at onset variance analysis. Neurology 58:702-708.

Wen W, Meinkoth JL, Tsien RY, Taylor SS (1995) Identification of a signal for rapid export of proteins from the nucleus. Cell 82:463-473.

Yamada M, Hayashi S, Tsuji S, Takahashi H (2001) Involvement of the cerebral cortex and autonomic ganglia in Machado-Joseph disease. Acta Neuropathol (Berl) 101:140-144. 